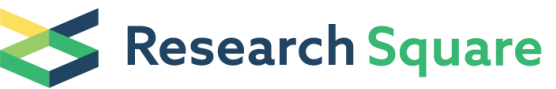

\section{Vibrational spectroscopy analysis of ligand efficacy in M2R}

Kota Katayama ( $\nabla$ katayama.kota@nitech.ac.jp )

Nagoya Institute of Technology

Kohei Suzuki

Nagoya Institute of Technology

\section{Ryoji Suno}

Kansai Medical University

\section{Ryoji Kise}

Tohoku University

Hirokazu Tsujimoto

Kyoto University

\section{So Iwata}

Kyoto University

\section{Asuka Inoue}

Tohoku University

\section{Takuya Kobayashi}

Kansai Medical University

\section{Hideki Kandori}

Nagoya Institute of Technology https://orcid.org/0000-0002-4922-1344

\section{Article}

Keywords: G protein-coupled receptors (GPCRs), ligand binding, human M2 muscarinic acetylcholine receptor (M2R)

Posted Date: April 16th, 2021

DOl: https://doi.org/10.21203/rs.3.rs-411771/v1

License: (c) (1) This work is licensed under a Creative Commons Attribution 4.0 International License. Read Full License

Version of Record: A version of this preprint was published at Communications Biology on November 23rd, 2021. See the published version at https://doi.org/10.1038/s42003-021-02836-1. 

2 Kota Katayama*1,2,3,8 , Kohei Suzuki ${ }^{1,8}$, Ryoji Suno ${ }^{4}$, Ryoji Kise ${ }^{5}$, Hirokazu Tsujimoto ${ }^{6}$, So Iwata ${ }^{6}$,

3 Asuka Inoue ${ }^{5}$, Takuya Kobayashi ${ }^{4,7}$, and Hideki Kandori*1,2

4

$5 \quad{ }^{1}$ Department of Life Science and Applied Chemistry, Nagoya Institute of Technology, Showa-ku,

6 Nagoya 466-8555, Japan

$7 \quad{ }^{2}$ OptoBioTechnology Research Center, Nagoya Institute of Technology, Showa-ku, Nagoya 8 466-8555, Japan

$9 \quad{ }^{3}$ PRESTO, Japan Science and Technology Agency, 4-1-8 Honcho, Kawaguchi, Saitama 332-0012,

10 Japan

$11{ }^{4}$ Department of Medical Chemistry, Kansai Medical University, Hirakata 573-1010, Japan

$12{ }^{5}$ Graduate School of Pharmaceutical Sciences, Tohoku University, Sendai, Miyagi 980-8578, 13 Japan

$14{ }^{6}$ Department of Cell Biology and Medical Chemistry, Graduate School of Medicine, Kyoto

15 University, Kyoto 606-8501, Japan

$16{ }^{7}$ Japan Agency for Medical Research and Development, Core Research for Evolutional Science 17 and Technology (AMED-CREST), Chiyoda-ku, Tokyo 100-0004, Japan

$18 \quad{ }^{8}$ These authors contributed equally

19

20 *Correspondence and requests for materials should be addressed to K.K. (email:

21 Katayama.kota@nitech.ac.jp), H.K. (email: kandori@nitech.ac.jp) 


\section{Abstract}

The intrinsic efficacy of ligand binding to G protein-coupled receptors (GPCRs) reflects the ability of the ligand to differentially activate its receptor to cause a physiological effect. Here we use attenuated total reflection-Fourier transform infrared (ATR-FTIR) spectroscopy to examine the ligand-dependent conformational changes in the human $\mathrm{M}_{2}$ muscarinic acetylcholine receptor $\left(\mathrm{M}_{2} \mathrm{R}\right)$. We show that different ligands affect conformational alteration appearing at the $\mathrm{C}=\mathrm{O}$ stretch of amide-I band in $\mathrm{M}_{2} \mathrm{R}$. Notably, ATR-FTIR signals strongly correlated with G-protein activation levels in cells. Together, we propose that amide-I band serves as an infrared probe to distinguish the ligand efficacy in $\mathrm{M}_{2} \mathrm{R}$ and paves the path to rationally design ligands with varied efficacy towards the target GPCR.

\section{Introduction}

G protein-coupled receptors (GPCRs) are one of the largest family of membrane proteins that induce most of the intracellular biological signalling upon ligand binding ${ }^{1}$. Therefore, understanding the molecular mechanism of GPCR-ligand interaction is vital to elucidating their physiological functions and pathologies. GPCR signalling utilizes a coupling mechanism between the extracellular facing ligand-binding pocket and the cytoplasmic domain of the receptor that selectively interacts with the signalling transducer such as G-proteins, $\beta$-arrestins and various other effectors ${ }^{2,3}$. Furthermore, the different levels of activation of GPCRs are selectively and specifically controlled by the type of ligand, commonly known as efficacy ${ }^{4-6}$. To date, ligands have been categorized into four groups: full agonists, partial agonists, neutral antagonists, and inverse agonists. Understanding the molecular mechanisms that determine the ligand efficacy of GPCRs is important for rational drug design. In addition, discovery of ligands that regulate a target activity has contributed largely to the understanding of both physiological and pathological processes. However, most methods of evaluating ligand efficacy use downstream biochemical 
and physiological responses that measures the second messenger productivity, protein phosphorylation, and the level of gene expression ${ }^{7-9}$, and therefore these methods cannot evaluate the ligand efficacy directly.

Over the last decade, a number of high-resolution X-ray crystal structures of GPCRs have been determined by using lipid cubic phase (LCP). In addition, recent advance of single particle analyses using cryo electron microscopy provided not only the inactive structures bound with either antagonist or inverse agonist, but also active structures bound with agonists and signal transducers ${ }^{10-13}$. These structures have elucidated key structural changes between the inactive and the active conformations of GPCRs, especially in the extracellular ligand-binding site and the cytoplasmic surface where the effector G-protein interacts ${ }^{10-13}$. The muscarinic acetylcholine receptor $2\left(\mathrm{M}_{2} \mathrm{R}\right)$, one of the most extensively studied GPCR has been crystallized with its inverse agonist 3-quinuclidinyl-benzilate $(\mathrm{QNB})^{14}$ or $\mathrm{N}$-methylscopolamine $(\mathrm{NMS})^{15}$, full agonist Iperoxo (Ixo) ${ }^{16}$, and effector $\mathrm{G}_{\mathrm{o}}$-protein ${ }^{17}$. Although these studies have provided important insights into the structural changes including the ligand pocket and TM6 movement mediated by the two classes of ligands at the atomic level, its application to a broad variety of ligands with different efficacies, especially partial agonists and neutral antagonists, is extremely challenging. This is partly because most of the ligands have similar chemical and structural properties and high their binding affinities $\left(\mathrm{K}_{\mathrm{i}} \leq 10 \mathrm{nM}\right)$ causes the GPCR receptors to adapt their low-energy stable conformations. In addition, these structural techniques capture only a snapshot, low-energy conformation, which lack the conformational heterogeneity, therefore these methods cannot fully explain the mechanism of the efficacies.

Spectroscopic techniques such as nuclear magnetic resonance (NMR) and double electron-electron resonance (DEER) have provided insights into the dynamic nature of GPCRs underpinning the conformational plasticity of different efficacy ligand binding ${ }^{18-23}$. However, both spectroscopy techniques require large quantities of pure protein, isotopic labelling and/or 
site-directed mutations, which might not be suitable for all membrane protein systems due to their low labelling efficiency, expression limitations, misfolding, or loss of function. Attenuated total reflection-Fourier transform infrared (ATR-FTIR) spectroscopy is a well-established spectroscopy technique to study protein conformational changes related to their function, such as enzymatic activation $^{24}$ or substrate or ligand recognition and binding ${ }^{25}$. By combining a two-liquid exchange system, perfusion-induced difference ATR-FTIR spectroscopy has been applied to analyse ion-protein and ligand-protein interactions for ion channel and transporter proteins, respectively ${ }^{26-31}$. Another important advantage of this method is that ATR-FTIR generally requires less than $5 \mu \mathrm{g}$ of pure protein reconstituted into a lipid bilayer, which makes it highly effective and economical to study GPCRs.

We have recently employed this technique on $\mathrm{M}_{2} \mathrm{R}$ to reveal its ligand binding mechanism with its natural agonist, acetylcholine (ACh) and its antagonist, atropine (Atro) ${ }^{32}$. While ACh-bound spectra showed large spectral changes of the amide-I band (the $\mathrm{C}=\mathrm{O}$ stretch of the $\alpha$-helix), Atro-bound spectra revealed an oppose spectral shift of amide-I, which indicates the different conformational changes that occur between an agonist and an antagonist binding to $\mathrm{M}_{2} \mathrm{R}$. Furthermore, by tracking the ligand concentration dependence on $\mathrm{M}_{2} \mathrm{R}$ activity and ligand binding/dissociation in real time, we could also measure physicochemical properties of ligand binding with $\mathrm{M}_{2} \mathrm{R}$. Based on these results, we hypothesize that ATR-FTIR could be positioned as a quick and economical structural analysis tool to examine the ligand binding with GPCRs.

To verify our hypothesis, here we perform systematic ligand binding-induced difference ATR-FTIR spectroscopy measurements on ligands with different efficacies (inverse agonists to full agonists). We observe distinct conformational changes among the agonists, partial agonists, and antagonists in the $\mathrm{C}=\mathrm{O}$ stetch of amide-I band, which correlates well with G-protein activity in the cells. Time-course ATR-FTIR spectral traces at amide-I band demonstrate differential kinetic patterns: fast dissociation for the full and partial agonists from $\mathrm{M}_{2} \mathrm{R}$ and slow or no 
dissociation for the antagonists and inverse agonists. Together, the amide-I band serves as an infrared probe to distinguish the ligand efficacy of $\mathrm{M}_{2} \mathrm{R}$. Additionally, our analysis demonstrate that chemically related ligands exhibit different efficacy.

\section{Results}

\section{Spectra of the agonists- and partial agonists-bound forms}

We selected four agonists that are structurally similar to ACh, including Metacholine (Meta), Arecholine (Are), Carbamylcholine (Carb), Iperoxo (Ixo), and three partial agonists with no structural similarity to ACh, including Pilocarpin (Pilo), McN-A-343 (McN), and Xanomeline (Xano) (Fig. 1 a). All ligand binding-induced ATR-FTIR difference spectra contained combined noise signals originating from the unbound ligand absorption, distortions from the buffer, absorption changes in water, and the baseline drift due to protein shrinkage (Extended Data Fig. 1-5). After removing these distortions, the baseline-corrected spectra were calculated as shown in Fig. 1b. The ATR-FTIR spectra of the agonist-bound forms were very similar in their spectral features, except for Ixo. As we observed in ACh-bound $\mathrm{M}_{2} \mathrm{R}$ spectra, all of the features including three dominant bands $1666(-) / 1656(+) / 1640(-) \mathrm{cm}^{-1}$ combination bands, positive $1687 \mathrm{~cm}^{-1}$ band, and positive $1246 \mathrm{~cm}^{-1}$ were detectable in Meta-, Are-, and Carb-bound spectra. A previous study reported that the combination bands around $1650 \mathrm{~cm}^{-1}$ are originated from $\mathrm{C}=\mathrm{O}$ stretch of amide-I band. Particularly, a $10 \mathrm{~cm}^{-1}$ down-shift from 1666 to $1656 \mathrm{~cm}^{-1}$ of amide-I band upon binding of ACh points to an outward movement of TM6 enabling the engagement with G-protein. Furthermore, two positive bands at 1687 and $1246 \mathrm{~cm}^{-1}$ were tentatively assigned to $\mathrm{C}=\mathrm{O}$ stretch of Asn $404^{6.52}$ (the numbers in parenthesis denote the residue position in the Ballesteros-Weinstein scheme $^{33}$ ) and C-O stretch of tyrosine lid which is comprised of the three conserved tyrosines (Tyr104 ${ }^{3.33}$, Tyr403 $3^{6.51}$, and Tyr426 $6^{7.39}$ ), respectively. Both, Asn $404^{6.52}$ and the tyrosine lid constitute the orthosteric ligand binding site of $\mathrm{M}_{2} \mathrm{R}$. Since these bands are conserved in Meta-, 
Are-, and Carb-bound spectra, these agonists exhibit similar binding modes and associated conformational changes in the $\mathrm{M}_{2} \mathrm{R}$ protein moiety.

Unlike ACh- and other agonists-bound spectra, Ixo-bound spectra clearly showed a distinctive spectral shift of amide-I band (Fig. 1b). Although the pair bands at $1666(-) / 1652$ $(-) / 1631(+) \mathrm{cm}^{-1}$ can be attributed to the $\mathrm{C}=\mathrm{O}$ stretch of amide-I, they showed around $20-30 \mathrm{~cm}^{-1}$ spectral downward shift as compared to other agonists-bound spectra. Ixo, being 100-fold more potent than $\mathrm{ACh}$ and classified as a super agonist of $\mathrm{M}_{2} \mathrm{R}^{34}$, was used to obtain the active $\mathrm{M}_{2} \mathrm{R}$ crystal structure. Previously, solution NMR study in combination with molecular dynamics (MD) simulations revealed significant protein conformational changes upon binding of full agonist and super agonist with $\mathrm{M}_{2} \mathrm{R}$. Major conformational changes were found in TM5 and TM6, which would be influenced by slight changes in the orthosteric-binding site of $\mathrm{M}_{2} \mathrm{R}^{22}$. Namely, Ixo binds deeper into the ligand binding pocket of $\mathrm{M}_{2} \mathrm{R}$ than Ach via a hydrogen bond with $\mathrm{Asn} 404^{6.52}$ and a water molecule near Asn404 $4^{6.5222}$. Interestingly, the Ixo-bound spectra shows a positive 1684 $\mathrm{cm}^{-1}$ band which tentatively originates from the $\mathrm{C}=\mathrm{O}$ stretch of Asn $404^{6.52}$ with a $3 \mathrm{~cm}^{-1}$ downward shift as compared to ACh-bound spectra (Fig. 1b). This suggests a stronger hydrogen bond interaction of Ixo with Asn $404^{6.52}$ than ACh. The observed changes in the hydrogen bond strength particular to Ixo-binding is likely the reason of the distinct TM conformational change detected as $20-30 \mathrm{~cm}^{-1}$ downward shift of amide-I band.

In contrast to agonists, partial agonists-bound spectra display relatively different spectral features. At around $1650 \mathrm{~cm}^{-1}$ region, the band intensity and the population of the combination band of amide-I (1666 (-)/1656 (+)/1640 (-) $\mathrm{cm}^{-1}$ in ACh-bound spectra) were altered upon partial agonists binding. However, the band frequencies were nearly identical to that of agonists-bound spectra. In Pilo- and McN-bound spectra, while the bands at $1667(-)$ or $1670(-) \mathrm{cm}^{-1}$ corresponding to the apo form are decreased, negative 1643 or $1649 \mathrm{~cm}^{-1}$ bands intensities were enhanced. These pattern of spectral shift of amide-I bands are similar to that of Atro-bound 
spectra (Fig. 1b). In contrast, Xano-bound spectra had $1666(-) / 1655(+) / 1643(-) \mathrm{cm}^{-1}$ combination band intensity similar to that of agonists-bound spectra. The decrease in band intensity of amide-I caused by partial agonists was consistent with their lower efficacy towards $\mathrm{M}_{2} \mathrm{R}$. Thus, the spectral shift pattern of the amide-I band suggests that it is reflected in the conformational equilibrium between the inactive state and active states of $\mathrm{M}_{2} \mathrm{R}$.

While similar protein structural changes were observed between agonists and partial agonists which result in equilibrium shift from inactive to active states, partial agonists-dependent conformational changes around ligand binding site were also observed. Similar to ACh-bound spectra, Pilo-bound spectra shows two positive bands at 1687 and $1246 \mathrm{~cm}^{-1}$, which originates from Asn $404^{6.52}$ and the tyrosine lid, respectively. Unlike Pilo-bound spectra, McN-bound spectra does not show the positive band at $1687 \mathrm{~cm}^{-1}$, and the positive band at $1246 \mathrm{~cm}^{-1}$ shifts to 1231 $\mathrm{cm}^{-1}$. We also observed a $7 \mathrm{~cm}^{-1}$ up shift in Asn404 $4^{6.52}$ signal to $1694 \mathrm{~cm}^{-1}$ and a $2 \mathrm{~cm}^{-1}$ down-shift in tyrosine lid signal to $1244 \mathrm{~cm}^{-1}$. These results suggest a different hydrogen bond strength between the nitrogen of Asn $404^{6.32}$ and the acetyl oxygen (in Pilo and $\mathrm{McN}$ ) or sulphur (in Xano) (Fig. 1a). This is one of the key reasons for the deferential activation of $\mathrm{M}_{2} \mathrm{R}$ by various classes of ligands.

\section{Spectra of the antagonist- and inverse agonist-bound forms}

Next, we investigated the conformational changes induced by antagonists and inverse agonists. Previous FTIR study showed that Atro-bound spectra clearly exhibited the different spectral shift pattern of amide-I as compared to the ACh-bound spectra. The two positive bands originating from Asn $404^{6.52}$ and the tyrosine lid were absent, which might suggest a weaker interaction of Atro with Asn $404^{6.52}$ and a loose connecting triad of tyrosine lid ${ }^{32}$. With respect to spectral features, Scopolamine (Scop)- and Ipratropium (Ipra)-bound spectra were similar with

Atro-bound spectra (Fig. 2b purple curves). Each antagonist-bound spectra possesses the 
combination bands of amide-I at $1666(-) / 1655(+) / 1643(-) \mathrm{cm}^{-1}$ for Scop and $1664(-) / 1653$ $(+) / 1643(-) \mathrm{cm}^{-1}$ for Ipra. As expected, the two ligand-binding site specific positive bands at 1687 and $1246 \mathrm{~cm}^{-1}$ are missing in both spectra, strongly indicating that all three antagonists (Atro, Scop, and Ipra) bind to the orthosteric site of $\mathrm{M}_{2} \mathrm{R}$ and induce a similar conformational change in the TM region. These results are consistent with the structural similarity between these antagonists. These antagonists differ only at cationic amine group, which forms an electrostatic interaction with Asp1033.32 35 .

In contrast to antagonists, inverse agonists-bound spectra show significantly different spectral features as compared to both antagonists- and agonists-bound spectra (Fig. 1b cyan curves). For N-methylscopolamine (NMS)-bound spectra, dominant peaks at $1661(+) / 1643(-)$ $\mathrm{cm}^{-1}$ will correspond to amide-I band at $1656(+) / 1643(-) \mathrm{cm}^{-1}$ as observed in antagonists-bound spectra. However, the corresponding negative $1666 \mathrm{~cm}^{-1}$ band is lacking in NMS-bound spectra. Additionally, the band around $1660 \mathrm{~cm}^{-1}$ is broadened. For tiotropium (Tio)-bound spectra, in addition to the amide-I pair bands at $1652(+) / 1640(-) \mathrm{cm}^{-1}$, a new positive band was observed at $1666 \mathrm{~cm}^{-1}$. The observed distinct spectral changes of amide-I band indicate conformational heterogeneity in both NMS- and Tio-bound structures of $\mathrm{M}_{2} \mathrm{R}$. This is consistent with previous NMR studies that revealed two conformations of $\mathrm{M}_{2} \mathrm{R}$ upon binding with $\mathrm{Tio}^{22}$. Notably, both inverse agonists-bound spectra showed no positive bands at 1687 and $1246 \mathrm{~cm}^{-1}$ originating from Asn $404^{6.52}$ and tyrosine lid, which is consistent with antagonists-bound spectra. Taken together, different patterns of spectral shift of amide-I and spectral changes of functional group of amino acids of the orthosteric binding site of $\mathrm{M}_{2} \mathrm{R}$ were observed, depending on the efficacy of the bound ligand.

\section{Correlation between relative intensities of the amide-I bands and the activation of}

\section{G protein}


To quantitatively examine the change in the amide-I band depending on the ligand efficacy,

199 the ratio of the band strength $\left(1656(+) / 1666(-) \mathrm{cm}^{-1}\right.$ in case of ACh-bound spectra, active state component) at high frequency to the band strength at low frequency $\left(1656(+) / 1640(-) \mathrm{cm}^{-1}\right.$ in case of ACh-bound spectra, inactive state component) was calculated by equation in Fig. 2a. The amide-I percent population was assumed to be the ligand efficacy (Fig. 2b and 2c). Strikingly, all agonists have an amide-I percent population $>1$, with the exception of Xano. The amide-I percent population for both the partial agonists and the antagonists were $<1$. The ligands, Ixo (super agonist) and NMS and Tio (inverse agonists) which gave a complex spectral variation, were excluded from the present analysis. Compared to Pilo and $\mathrm{McN}$ among partial agonists, Xano stabilizes a higher population of active-like $\mathrm{M}_{2} \mathrm{R}$ conformation, which is characterized by the outward movement of TM6. On the other hand, among the antagonists, Ipra has a higher ratio of active conformation than Atro and Scop.

We assumed that the amide-I percent population correlates with $\mathrm{M}_{2} \mathrm{R}$ signalling efficacy. To quantitatively compare the two parameters, we calculated changes in the intensity of the amide-I band by infrared spectroscopy and measured the efficacies of each ligand toward $\mathrm{G}_{\mathrm{i}}$-protein activation using a NanoBiT G-protein dissociation assay (Extended Data Fig. 6) ${ }^{36}$. The functional assays show that three agonists; Meta, Are, and Carb which have similar chemical structures, 215 show almost identical $\mathrm{G}_{\mathrm{i}}$-protein activity as $\mathrm{ACh}$-bound $\mathrm{M}_{2} \mathrm{R}$ (Fig. 3a). Ixo represents higher 216 G-protein activation than ACh, which is consistent with the reported property of super agonist 217 (Fig. 3a) $)^{34}$. We found that partial agonists, Pilo, $\mathrm{McN}$, and Xano exhibit decreased $\mathrm{G}_{\mathrm{i}}$ signalling against their relative $\mathrm{G}_{\mathrm{i}}$-protein efficacy to $\mathrm{ACh}$. The amide-I percent population correlated relative to ACh. By contrast, the tested antagonists showed poor (Ipra; 6.3\% of ACh) or undetectable (Atro and Scop) $\mathrm{G}_{\mathrm{i}}$-dissociation activity (Fig. 3a).

Next, we plotted the amide-I percent population for agonists, partial agonists, and antagonists remarkably well with agonist efficacy in promoting $\mathrm{G}_{\mathrm{i}}$ coupling $\left(E_{\max }\right)$ (Fig. 3b), but did not 
correlated with their potency values, pEC50 (Extended Data Fig. 7). In contrast, from the amide-I

percent population, the antagonists can induce an equilibrium shift to the active state at a certain rate, but has a minimal or no apparent effect on $\mathrm{G}_{\mathrm{i}}$-protein activation (Fig. $3 \mathrm{~b}$, purple). These results indicate that $\mathrm{M}_{2} \mathrm{R}$ shows more conformational plasticity than other class A type of GPCRs such as $\beta_{2} \mathrm{AR}^{18}$, turkey $\beta_{1} \mathrm{AR}^{19}, \mu \mathrm{OR}^{20}$, and $\alpha_{1 \mathrm{~A}}-\mathrm{AR}^{21}$. Nevertheless, the band shift changes in amide-I can be used as an infrared probe of agonist efficacy that promotes $\mathrm{G}_{\mathrm{i}}$-coupling.

\section{Implications of ligand-dependent dissociation kinetics from $\mathbf{M}_{2} \mathbf{R}$}

Additional insights on the discrimination of ligand efficacy from ATR-FTIR measurements can be obtained by examining the ligand dissociation kinetics $\left(\mathrm{k}_{\text {off }}\right)$ from $\mathrm{M}_{2} \mathrm{R}$ (Fig. 4a). In a previous study, the time evolution of the difference ATR-FTIR spectra over the course of the experiment showed different dissociation events between ACh and Atro with $\mathrm{M}_{2} \mathrm{R}$. While the band intensity of amide-I in ACh-bound spectra decreased gradually after exchanging the buffer without ACh, the band intensity in Atro-bound spectra did not decrease during the dissociation phase artificially caused by the buffer exchange. These behaviours are consistent with their $\mathrm{K}_{\mathrm{i}}$ values (ACh; $10 \mu \mathrm{M}^{37}$, Atro; $0.8 \mathrm{nM}^{38,39}$ ). As shown in Fig. 4b, dissociation kinetics of Meta and Carb was similar to ACh-bound $\mathrm{M}_{2} \mathrm{R}$. These results are consistent with similar ligand-bound spectral features observed as shown in Fig. 1b. Although Are-bound $\mathrm{M}_{2} \mathrm{R}$ also displayed similar spectral features to that of ACh-bound spectra (Fig. 1b), its dissociation rate suggests slower kinetics. This is probably due to the steric hindrance caused by the Are-specific chemical structure possessing tetrahydropyridine, which makes it difficult to dissociate from the receptor.

On the other hand, Ixo exhibited the slowest dissociation kinetics. This result also indicates difficulty in dissociating from the receptor and corresponds to previous NMR results suggesting that Ixo binds more deeply in the ligand binding pocket than $\mathrm{ACh}^{22}$.

For partial agonists, while we observe fast dissociation kinetics of Pilo and $\mathrm{McN}$ like for ACh, 
Xano exhibited extremely slow $\mathrm{k}_{\text {off. }}$ This can be likely explained by the tetrahydropyridine ring 249 present in the chemical structures of both Are and $\mathrm{Xano}^{40}$. In addition, Xano is known to act as the strongest G-protein biased agonist of $\mathrm{M}_{2} \mathrm{R}^{41}$, and one of the underlying reasons for its strong G-protein biased signalling could be a longer dissociation kinetics of the ligand-receptor complex. With the exception of Are, Ixo, and Xano, all agonists and partial agonists we used in the present study dissociated from $\mathrm{M}_{2} \mathrm{R}$ by buffer exchange, whereas all antagonists and inverse agonists did not show any dissociation from the receptor, which are consistent with their strong binding. Given that the spectra of the inverse agonists-bound form are completely unique in shape compared to other ligands-bound spectra, ligand binding-induced difference ATR-FTIR spectroscopy appears to be a versatile tool to distinguish between antagonist and inverse agonist binding to GPCRs.

\section{Discussion}

changes of $\mathrm{M}_{2} \mathrm{R}$ when bound to various ligands. The amide-I band shift pattern of $\alpha$-helical $\mathrm{C}=\mathrm{O}$ stretch demonstrated that different classes of $\mathrm{M}_{2} \mathrm{R}$ ligands altered the population between inactive and active states, with the respect to the protein conformational changes, including an outward and $\alpha_{1 \mathrm{~A}}-\mathrm{AR}^{21}$, the chemical shifts reflecting receptor conformations for different ligands showed 270 a linear correlation with their ligand efficacies. On the other hand, a similar NMR analysis for $271 \mathrm{M}_{2} \mathrm{R}$ did not show a strong correlation with ligand efficacy, suggesting that $\mathrm{M}_{2} \mathrm{R}$ showed a 272 complex conformational heterogeneity ${ }^{22}$. In the present study, by combining ATR-FTIR 
spectroscopy with functional cell-based $\mathrm{G}_{\mathrm{i}}$-protein assays, we found a correlation between the amide-I percent population and ligand efficacy for both full and partial agonists, but some ligands such as Ixo or Xano showed complex spectral features and were outliers. Furthermore, all the amide-I percent population of antagonists-bound spectra did not show linear correlation with cell-based $\mathrm{G}_{\mathrm{i}}$-protein assay. Rather, the amide-I percent population analysis indicates that the equilibrium proportions of active and inactive states of $\mathrm{M}_{2} \mathrm{R}$ is similar between partial agonists and antagonists. On the other hand, Asn $404^{6.52}$ and tyrosine lid are likely involved in not only direct ligand binding, but also allosteric activation of G-protein because the changes in Asn404 ${ }^{6.52}$ and Tyrosine lid are observed in the agonists- and partial agonists-bound spectra, but not in the antagonists-bound spectra. These results demonstrate that $\mathrm{M}_{2} \mathrm{R}$ shows more conformational plasticity than other class A type of GPCRs such as $\beta_{2} \mathrm{AR}^{18}$, turkey $\beta_{1} \mathrm{AR}^{19}, \mu \mathrm{OR}{ }^{20}$, and $\alpha_{1 \mathrm{~A}-\mathrm{AR}}{ }^{21}$, and therefore future application of same ATR-FTIR measurements to these GPCRs may lead to a confirmation. both NMS and Tio are significantly different from other ligands-bound spectra, especially in the amide-I band region. The result of NMS-bound spectra showed a broadening of the amide-I band, whereas the Tio-bound spectra was a bilobed amide-I band, indicative of unique conformational changes as compared with other types of ligands. So, what are the inverse agonist-specific structural changes compared to an antagonist, even though both ligands reduce the activation of GPCRs? Recently determined structure of $M_{1} R$ bound with Atro ${ }^{42}$ clearly showed significant conformational differences as compared to Tio-bound $\mathrm{M}_{1} \mathrm{R}^{43}$ at the extracellular end of TM5, where a slight inward displacement at TM5 was observed in the Atro-bound form relative to Tio binding. Most likely, the two arene ring of Tio causes steric clashes with TM5, which prevents the inward movement of TM5 at the end of extracellular side like in Atro-bound $\mathrm{M}_{1} \mathrm{R}$. Thus, one of the two positive bands of amide-I at $1666 \mathrm{~cm}^{-1}$ in the Tio-bound spectra may correspond to a 
change in TM5 at extracellular region, while the other band at $1652 \mathrm{~cm}^{-1}$ being specific to TM6 motion.

On the other hand, NMS does not have two arene rings like Tio, but rather a very similar 301 chemical structure to Scop (Fig. 1a). Nonetheless, how NMS can exhibit efficacy as an inverse agonist? The only difference is the presence or absence of a methyl group in tropane alkaloid between Scop and NMS. So, does the difference in efficacy depend solely on the presence or absence of methyl groups between Scop (antagonist) and NMS (inverse agonist)? To investigate this possibility, we measured ligand-binding induced difference ATR-FTIR spectroscopy of tropane alkaloid, respectively. NBS-bound spectra was exactly identical to Scop-bound spectra, while Oxitro-bound spectra exhibited a complex (broadening and/or bilobed) spectral feature like in NMS-bound spectra, especially at the amide-I band (Fig. 6a). This result suggests that NBS acts as an antagonist and Oxitro as an inverse agonist. The inactive structures of Atro-bound form of $\mathrm{M}_{1} \mathrm{R}^{42}$ and NMS-bound form of $\mathrm{M}_{2} \mathrm{R}^{15}$ show a common involvement of Asp103 3.32 in the interaction with the tropane alkaloid (Fig. 6b). Thus, to function as an inverse agonist, the length of the tropane alkaloid side chain should not be too long or too short, and only methyl or ethyl conformational changes specific to the binding of an inverse agonist or antagonist remains difficult. This is partly because the crystal structures of both inverse agonist- and antagonist-bound forms show common structural changes, including an outward movement of 321 seen in several structures of class A GPCR-ligand complexes ${ }^{44}$. On the other hand, the ATR-FTIR spectroscopic analysis performed in this study clearly distinguishes inverse agonists- and 
antagonists-bound forms of $\mathrm{M}_{2} \mathrm{R}$ by detecting the difference in the spectral feature of amide-I

324 band caused by the difference in carbon chain length, suggestive of its broad implications in rational drug design of GPCRs (Extended Data Fig. 9).

Although we succeeded in distinguishing orthosteric ligand efficacy in $M_{2} R$, all of them that we used in this study are water-soluble ligands. Our measurement system, which uses lipid reconstituted samples, is incompatible with measurement for lipid-soluble ligands because of the effect of protein shrinkage associated with lipid-ligand interaction. Therefore, future improvements in measurement system is clearly needed to evaluate the efficacy of any ligand. Moreover, since our method proved to be able to evaluate the efficacy of ligands for only one type of receptor, it is necessary to demonstrate the general applicability of our method to a wide range of other GPCRs in the future.

In summary, we have described a novel method for the quantitative evaluation of efficacy of four types ligands including agonist, partial agonist, antagonist, and inverse agonist from the vibrational perspective of amide-I band change in $\mathrm{M}_{2} \mathrm{R}$ embedded into lipid environment using ATR-FTIR spectroscopy. This biophysical technique can also provide the physicochemical parameters such as dissociation constant and dissociation rate constant of ligand simultaneously. Overall, the vibrational spectroscopic method reported herein provides a promising strategy for measuring ligand efficacy at a wide variety of GPCRs.

\section{Methods}

\section{Protein expression and purification}

The $\mathrm{M}_{2} \mathrm{R}$ fused with BRIL at ICL3 position $\left(\mathrm{M}_{2} \mathrm{R}\right)$ was expressed and purified as described previously $^{15}$, except for some minor modifications for reconstitution into the membrane. Briefly, C-terminally His-tagged $\mathrm{M}_{2} \mathrm{R}$-BRIL with the hemagglutinin (HA) signal sequence followed by an N-terminal FLAG tag was expressed in Sf9 insect cells. Cells were infected at a density of 3-4 $\times$ 
$10^{6}$ cells/mL and grown for $48 \mathrm{~h}$ at $27^{\circ} \mathrm{C}$. Sf9 cells were lysed by osmotic shock in the presence of $10 \mu \mathrm{M}$ atropine (Sigma-Aldrich). The lysed membranes were solubilized using a buffer containing $30 \mathrm{mM}$ HEPES-NaOH ( $\mathrm{pH} 7.5), 0.75 \mathrm{M} \mathrm{NaCl}, 5 \mathrm{mM}$ imidazole, $1 \%$ (w/v) n-dodecyl- $\beta$-D-maltopyranoside (DDM; anatrace), $0.2 \%$ sodium cholate (Wako), $1 \mathrm{mg} \mathrm{mL} \mathrm{mL}^{-1}$ iodoacetamide (Dojindo), and Complete Protease inhibitor (Roche) for $1 \mathrm{~h}$ at $4{ }^{\circ} \mathrm{C}$. The supernatant was isolated by ultracentrifugation for $30 \mathrm{~min}$ at $140,000 \times g$ and incubated with Ni-NTA Sepharose Superflow resin (Qiagen) overnight at $4{ }^{\circ} \mathrm{C}$. After binding, the resin was washed with Ni-NTA wash buffer: $30 \mathrm{mM}$ HEPES-NaOH (pH 7.5), $0.75 \mathrm{M} \mathrm{NaCl}, 0.1 \%$ (w/v) DDM, $0.02 \%(\mathrm{w} / \mathrm{v})$ sodium cholate, $5 \mathrm{mM}$ imidazole and $10 \mu \mathrm{M}$ atropin. The protein was then eluted with Ni-NTA elution buffer: $30 \mathrm{mM}$ HEPES-NaOH (pH 7.5), $0.75 \mathrm{M} \mathrm{NaCl}, 0.1 \%(\mathrm{w} / \mathrm{v})$ DDM, $0.02 \%(\mathrm{w} / \mathrm{v})$ sodium cholate, $5 \mathrm{mM}$ imidazole and $10 \mu \mathrm{M}$ atropine, $500 \mathrm{mM}$ imidazole. The eluate was supplemented with $2 \mathrm{mM}$ calcium chloride and loaded onto an anti-FLAG M1 affinity resin (Sigma). The receptor was eluted from the anti-FLAG M1 affinity resin with a buffer of $20 \mathrm{mM}$ HEPES-NaOH (pH 7.5), $0.1 \mathrm{M} \mathrm{NaCl}, 0.01 \%(\mathrm{w} / \mathrm{v}) \mathrm{DDM}, 10 \mu \mathrm{M}$ atropine, 0.2 $\mathrm{mg} \mathrm{mL}^{-1}$ FLAG peptide and $5 \mathrm{mM}$ EDTA. Finally, protein was purified by Superdex 200 Increase size exclusion column (GE Healthcare) in a buffer of $20 \mathrm{mM}$ HEPES-NaOH (pH 7.5), $0.1 \mathrm{M}$ $\mathrm{NaCl}, 0.01 \%(\mathrm{w} / \mathrm{v}) \mathrm{DDM}$.

\section{Protein reconstitution}

For ATR-FTIR measurements, detergent-solubilized $\mathrm{M}_{2} \mathrm{R}$ was reconstituted into asolectin liposomes with a 20 -fold molar excess. The detergent molecule was removed by incubation with Bio-beads SM-2 (Bio-Rad, CA, USA). After removal of Biobeads, the lipid-reconstituted $\mathrm{M}_{2} \mathrm{R}$ was collected by ultracentrifugation for $30 \mathrm{~min}$ at $222,000 \times \mathrm{g}$ at $4{ }^{\circ} \mathrm{C}$. After several cycles of wash/spin, lipid-reconstituted $\mathrm{M}_{2} \mathrm{R}$ was suspended in a buffer composed of $5 \mathrm{mM}$ phosphate (pH 7.5) and $10 \mathrm{mM} \mathrm{KCl}$. 


\section{Measurement of ligand binding-induced difference ATR-FTIR spectroscopy}

A $2 \mu \mathrm{L}$ aliquot of the lipid-reconstituted $\mathrm{M}_{2} \mathrm{R}$ suspensions was placed on the surface of a silicon ATR crystal (three internal total reflection, Smith Detection, UK. After it was dried in a gently natural drying, the sample was rehydrated with a solvent containing $200 \mathrm{mM}$ phosphate (pH 7.5) buffer with $140 \mathrm{mM} \mathrm{NaCl}, 3 \mathrm{mM} \mathrm{MgCl}_{2}$ at a flow rate of $0.6 \mathrm{~mL} \mathrm{~min}^{-1}$ through a flow cell, of which the temperature was maintained at $20{ }^{\circ} \mathrm{C}$ by circulating water. ATR-FTIR spectra were first recorded at $2 \mathrm{~cm}^{-1}$ resolution, using an FTIR spectrometer (Bio-rad FTS7000, Agilent, CA, USA) equipped with a liquid nitrogen-cooled MCT detector (an average of 768 interferograms). After the FTIR spectrum had been recorded in the second buffer with $1 \mathrm{mM}$ ligand, the difference FTIR spectrum was calculated by subtracting the data obtained for the first and second buffer. The cycling procedure was repeated two to seven times, and the difference spectra were calculated as the average of the presence minus absence spectra of ligand. The spectral contributions of the unbound ligand, the protein/lipid shrinkage, and water/buffer components were corrected (Extended Data Fig. 2-5).

\section{NanoBiT G-protein dissociation assay}

$\mathrm{M}_{2} \mathrm{R}$-induced G-protein dissociation was measured by a NanoBiT-G-protein dissociation assay ${ }^{36}$, in which the interaction between a $G \alpha$ subunit and a G $\beta \gamma$ subunit was monitored by the NanoBiT system (Promega). Specifically, a NanoBiT-G $\mathrm{G}_{11}$ protein consisting of $\mathrm{G}_{\mathrm{i} 1}$ subunit fused with a

393 large fragment (LgBiT) at the $\alpha$-helical domain and an $\mathrm{N}$-terminally small fragment 394 (SmBiT)-fused $\mathrm{G} \gamma_{2}$ subunit with a C68S mutation was expressed along with untagged G $\beta_{1}$ subunit and $\mathrm{M}_{2} \mathrm{R}$. HEK293A cells were seeded in a 10-cm culture dish at a concentration of $2 \mathrm{x}$

$39610^{5}$ cells $\mathrm{mL}^{-1}(10 \mathrm{~mL}$ per well in DMEM (Nissui) supplemented with $10 \%$ fetal bovine serum 397 (Gibco), glutamine, penicillin and streptomycin), one day before transfection. Transfection 
solution was prepared by combining $25 \mu \mathrm{L}$ (per dish hereafter) of polyethylenimine (PEI) Max solution (1 mg mL ${ }^{-1}$; Polysciences), $1 \mathrm{~mL}$ of Opti-MEM (Thermo Fisher Scientific) and a plasmid mixture consisting of $1 \mu \mathrm{g} \mathrm{M}_{2} \mathrm{R}$ (or an empty plasmid for mock transfection), $500 \mathrm{ng}$ LgBiT-containing $\mathrm{G} \alpha_{\mathrm{i} 1}$ subunit, $2.5 \mu \mathrm{g} \mathrm{G} \beta_{1}$ subunit and $2.5 \mu \mathrm{g}$ SmBiT-fused $\mathrm{G} \gamma_{2}$ subunit (C68S). After an incubation for 1 day, the transfected cells were harvested with $0.5 \mathrm{mM}$ EDTA-containing Dulbecco's PBS, centrifuged and suspended in $10 \mathrm{~mL}$ of HBSS containing $0.01 \%$ bovine serum albumin (BSA; fatty acid-free grade; SERVA) and 5 mM HEPES (pH 7.4) (assay buffer). The cell suspension was dispensed in a white 96-well plate at a volume of $80 \mu \mathrm{L}$ per well and loaded with $20 \mu \mathrm{L}$ of $50 \mu \mathrm{M}$ coelenterazine (Carbosynth) diluted in the assay buffer. After a $2 \mathrm{~h}$ incubation at room temperature, the plate was measured for baseline luminescence (Spectramax L, Molecular Devices) and a titrated test ligand (20 $\mu \mathrm{L}$; $6 \mathrm{X}$ of final concentrations) was manually added. The plate was immediately read at room temperature for the following $5 \mathrm{~min}$ as a kinetics mode, at measurement intervals of $20 \mathrm{sec}$. The luminescence counts over 3-5 min after ligand addition were averaged and normalized to the initial count. The fold-change values were further normalized to that of vehicle-treated samples and used to plot the G-protein dissociation response. Using the Prism 8 software (GraphPad Prism), the G-protein dissociation signals were fitted to a four-parameter sigmoidal concentration-response curve. For each replicate experiment, the parameter Span (= Top - Bottom) of individual ligands was normalized to ACh and the resulting $E_{\max }$ values were used as efficacy.

\section{Data Availability}

The data supporting the findings of this study are available in the article, Supplementary Information, and if applicable, from the corresponding author on request. 


\section{Reference}

4231 Kenakin, T. Drug efficacy at G protein-coupled receptors. Annu. Rev. Pharmacol. Toxicol.

2 Weis, W. I ; Kobilka, Annu Rev Biochem. 2018, 87, 897-919..

Manglik, A.; Kim, T. H.; Masureel, M.; Altenbach, C.; Yang, Z.; Hilger, D.; Lerch, M. T.; Kobilka, T. S.; Thian, F. S.; Hubbell, W. L.; Prosser, R. S.; Kobilka, B. K. Structural insights into the dynamics process of $\beta_{2}$-adrenergic receptor signalling. Cell 2015, 161, 1101-1111.

\section{Kobilka, B. K. \& Deupi, X. Conformational complexity of G-protein-coupled receptors.} Trends Pharmacol. Sci. 28, 397-406 (2007).

Rosenbaum, D. M., Rasmussen, S. G. \& Kobilka, B. K. The structure and function of G-protein-coupled receptors. Nature 459, 356-363 (2009).

Wacker, D., Stevens, R. C. \& Roth, B. L. How ligands illuminate GPCR molecular pharmacology. Cell 170, 414-427 (2017).

pharmacology. Trends Pharmacol. Sci. 32, 189-196 (2011).

Kenakin, T. Efficacy at G-protein-coupled receptors. Nat. Rev. Drug. Discov. 1, 103-110 (2002).

9 Herenbrink, C. K., Sykes, D. A., Donthamsetti, P., Canals, M., Coudrat, T., Shonberg, J., Scammells, P. J. Capuano, B., Sexton, P. M., Charlton, S. J., Javitch, J. A., Christopoulos, A. \& Lane, J. R. The role of kinetic context in apparent biased agonism at GPCRs. Nat. Commun. 7, 10842-10856 (2016).

11 Warne, T., Edwards, P. C., Doré, A. S., Leslie, A. G. W. \& Tate, C. G. Moleular basis for high-affinity agonist binding in GPCRs. Science 364, 775-778 (2019).

12 Liu, X., Xu, X., Hilger, D., Aschauer, P., Tiemann, J. K. S., Du, Y., Liu, H., Hirata, K., Sun, X., Guixà-González, R., Mathiesen, J. M., Hildebrand, P. W. \& Kobilka, B. K. Structural insights into the process of GPCR-G protein complex formation. Cell. 177, 1243-1251 (2019).

13 García-Nafría, J. \& Tate, C. G. Cryo-electron microscopy: Moving beyond X-ray crystal structures for drug receptors and drug development. Annu. Rev. Pharmacol. Toxicol. 60, 51-71 (2020).

14 Haga, K., Kruse, A. C., Asada, H., Yurugi-Kobayashi, T., Shiroishi, M., Zhang, C., Weis, W. I., Okada, T., Kobilka, B. K., Haga, T. \& Kobayashi, T. Structure of the human M2 muscarinic acetylcholine receptor bound to an antagonist. Nature 482, 547-551 (2012). 
15 Suno, R., Lee, S., Maeda, S., Yasuda, S., Yamashita, K., Hirata, K., Horita, S., Tawaramoto M. S., Tsujimoto, H., Murata, T., Kinoshita, M., Yamamoto, M., Kobilka, B. K., Vaidehi, N., Iwata, S. \& Kobayashi, T. Structural insights into the subtype-selective antagonist binding to the $\mathrm{M}_{2}$ muscarinic receptor. Nat. Chem. Biol. 14, 1150-1158 (2018).

16 Kruse, A. C., Ring, A. M., Manglik, A., Hu, J.; Hu, K., Eitel, K., Hübner, H., Pardon, E., Valant, C., Sexton, P. M., Christopoulos, A., Felder, C. C., Gmeiner, P., Steyaert, J., Weis, W. I., Garcia, K. C., Wess, J. \& Kobilka, B. K. Activation and allosteric modulation of a muscarinic acetylcholine receptor. Nature 504, 101-106 (2013).

17 Maeda, S., Qu, Q., Robertson, M. J., Skiniotis, G. \& Kobilka, B. K. Structures of the M $_{1}$ and $\mathrm{M}_{2}$ muscarinic acetylcholine receptor/G-protein complexes. Science 364, 552-557 (2019).

18 Kofuku, Y., Ueda, T., Okude, J., Shiraishi, Y., Kondo, K., Maeda, M., Tsujishita, H. \& Shimada, I. Efficacy of the $\beta_{2}$-adrenergic receptor is determined by conformational equilibrium in the transmembrane region. Nat. Commun. 3, 1045-1053 (2012).

19 Solt, A. S., Bostock, M. J., Shrestha, B., Kumar, P., Warner, T., Tate, C. G. \& Nietlispach, D. Insight into partial agonism by observing multiple equilibria for ligand-bound and Gs-mimetic nanobody-bound $\beta_{1}$-adrenergic receptor. Nat. Commun. 8, 1795-1806 (2017).

20 Okude, J., Ueda, T., Kofuku, Y., Sato, M., Nobuyama, N., Kondo, K., Shiraishi, Y., Mizumura, T., Onishi, K., Natsume, M., Maeda, M., Tsujishita, H., Kuranaga, T., Inoue, M. \& Shimada, I. Identification of a conformational equilibrium that determines the efficacy and functional selectivity of the $\mu$-opioid receptor. Angew. Chem. Int. Ed. 54, 15771-15776 (2015).

21 Wu, F-J., Williams, L. M., Abdul-Ridha, A., Gunatilaka, A., Vaid, T. M., Kocan, M., Whitehead, A. R., Griffin, M. D. W., Bathgate, R. A. D., Scott, D. J. \& Gooley, P. R. Probing the correation between ligand efficacy and conformaitonal diversity at the $\alpha_{1 \mathrm{~A}}$-adrenoreceptor reveals allosteric coupling of its microswitches. J. Biol. Chem. 295, 7404-7417 (2020).

22 Xu, J., Hu, Y., Kaindl, J., Risel, P., Hübner, H., Maeda, S., Niu, X., Li, H., Gmeiner, P., Jin, C. \& Kobilka, B. K. Conformational complexity and dynamics in a muscarinic receptor revealed by NMR spectroscopy. Molecular Cell 75, 1-15 (2019).

23 Wingler, L. M., Elgeti, M., Hilger, D., Latorraca, N. R., Lerch, M. T., Staus, D. P., Dror, R. O., Kobilka, B. K., Hubbell, W. L. \& Lefkowits, R. J. Angiotensin analogs with divergent bias stabilize distinct receptor conformations. Cell 176, 468-478 (2019).

24 Kumar, S. \& Barth, A. Following enzyme activity with infrared spectroscopy. Sensors 10, 2626-2637 (2010).

25 Iwaki, M., Cotton, N. P. J., Quirk, P. G., Rich, P. R. \& Baz Jackson, J. Molecular recognition between protein and nicotinamide dinucleotide in intact, proton-translocating transhydrogenase studied by ATR-FTIR spectroscopy. J. Am. Chem. Soc. 128, 2621-2629 
(2006).

26 Kitade, Y., Furutani, Y., Kamo, N. \& Kandori, H. Proton release group of pharaonic phoborhodopsin revealed by ATR-FTIR spectroscopy. Biochemistry 48, 1595-1603 (2009).

27 Jiang, X., Zaitseva, E., Schmidt, M., Siebert, F., Engelhard, M., Schlesinger, R., Ataka, K., Vogel, R. \& Heberle, J. Resolving voltage-dependent structural changes of a membrane photoreceptor by surface-enhanced IR difference spectroscopy. Proc. Natl. Acad. Sci. USA 105, 12113-12117 (2008).

28 Doki, S., Kato, H. E., Solcan, N., Iwaki, M., Koyama, M., Hattori, M., Iwase, N., Tsukazaki, T., Sugita, Y., Kandori, H., Newstead, S., Ishitani, R. \& Nureki, O. Proc. Natl. Acad. Sci. USA 110, 11343-11348 (2013).

29 Furutani, Y., Murata, T. \& Kandori, H. Sodium or lithium ion-binding-induced structural changes in the K-ring of V-ATPase from Enterococcus hirae revealed by ATR-FTIR spectroscopy. J. Am. Chem. Soc. 133, 2860-2863 (2011).

30 Katayama, K., Furutani, Y., Iwaki, M., Fukuda, T., Imai, H. \& Kandori, H. "In situ" observation of the role of chloride ion binding to monkey green sensitive visual pigment by ATR-FTIR spectroscopy. Phys. Chem. Chem. Phys. 20, 3381-3387 (2018).

31 Katayama, K., Nakamura, S., Sasaki, T., Imai, H. \& Kandori, H. Role of Gln114 in spectral tuning of a long-wavelength sensitive visual pigment. Biochemistry 58, 2944-2952 (2019).

32 Katayama, K., Suzuki, K., Suno, R., Tsujimoto, H., Iwata, S., Kobayashi, T. \& Kandori, H. Ligand binding-induced structural chnages in the $\mathrm{M}_{2}$ muscarinic acetylcholine receptor revealed by vibrational spectroscopy. J. Phys. Chem. Lett. 10, 7270-7276 (2019).

33 Ballesteros, J. A. \& Weinstein, H. Integrated methods for the construction of three-dimensional models and computational probing of structure-function relationships in G protein-coupled receptors. Methods Neurosci. 336-428 (1995).

34 Langmead, C. J. \& Christopoulos, A. Supra-physiological efficacy at GPCRs: superstition or super agonists? Br. J. Pharmacol. 169, 353-356 (2013).

35 Heitz, F., Holzwarth, J. A., Gies, J. P., Pruss, R. M., Trumpp-Kallmeyer, S., Hibert, M. F. $\&$ Guenet, C. Site-directed mutagenesis of the putative human muscarinic $\mathrm{M}_{2}$ receptor binding site. Eur. J. Pharmacol. 380, 183-195 (1999).

36 Inoue, A., Raimondi, F., Kadji, F. M. N., Singh, G., Kishi, T., Uwamizu, A., Ono, Y., Shinjo, Y., Ishida, S., Arang, N., Kawakami, K., Gutkind, J. S., Aoki, J. \& Russell, R. B. Illuminating G-protein-coupling selectivity of GPCRs. Cell 177, 1933-1947 (2019).

37 Cheng, K., Khurana, S., Chen, Y., Kennedy, R. H., Zimniak, P. \& Raufman, J. P. Lithocholylcholine, a bile acid/acetylcholine hybrid, is a muscarinic receptor antagonist. $J$. Pharmacol. Exp. Ther. 303, 29-35 (2002).

38 Kashihara, K., Varga, E. V., Waite, S. L., Roeske, W. R. \& Yamamura, H. I. Cloning of the 
rat $\mathrm{m} 3, \mathrm{~m} 4$ and $\mathrm{m} 5$ muscarinic acetylcholine receptor genes by the Polymerase Chain Reaction (PCR) and the pharmacological characterization of the expressed genes. Life Sci. 51, 955-971 (1992).

39 Kovacs, I., Yamamura, H. I., Waite, S. L., Varga, E. V. \& Roeske, W. R. Pharmacological comparison of the cloned human and rat $\mathrm{M}_{2}$ muscarinic receptor genes expressed in the murine fibroblast (B82) cell line. J. Pharmacol. Exp. Ther. 284, 500-507 (1998).

40 Shannon, H. E., Bymaster, F. P., Calligaro, D. O., Greenwood, B., Mitch, C. H., Sawyer, B. D., Ward, J. S., Wong, D. T., Olesen, P. H., Sheardown, M. J. et al. Xanomeline: a novel muscarinic receptor agonist with functional selectivity for $\mathrm{M}_{1}$ receptors. J. Pharmacol. Exp. Ther. 269, 271-281 (1994).

41 Jakubík, J., El-Fakahany, E. E. \& Dolezal, V. Differences in kinetics of xanomeline binding and selectivity of activation of $\mathrm{G}$ proteins at $\mathrm{M}_{1}$ and $\mathrm{M}_{2}$ muscarinic acetylcholine receptors. Mol. Pharmacol. 70, 656-666 (2006).

42 Maeda, S., Xu, J., Kadji, F. M. N., Clark, M. J., Zhao, J., Tsutsumi, N., Aoki, J., Sunahara, R. K., Inoue, A., Garcia, K. C. \& Kobilka, B. K. Structure and selectivity engineering of the $\mathrm{M}_{1}$ muscarinic receptor toxin complex. Science. 369, 161-167 (2020).

43 Thal, D. M., Sun, B., Feng, D., Nawaratne, V., Leach, K., Felder, C. C., Bures, M. G., Evans, D. A., Weis, W. I., Bachhawat, P., Kobilka, T. S., Sexton, P. M., Kobilka, B. K. \& Christopoulos, A. Crystal structures of the M1 and M4 muscarinic acetylcholine receptors. Nature 531, 335-340 (2016).

44 Yin, W., Zhou, X. E., Yang, D., de Waal, P. W., Wang, M., Dai, A., Cai, X., Huang, C-Y., Liu, P., Wang, X., Yin, Y., Liu, B., Zhou, Y., Wang, J., Liu, H., Caffrey, M., Melcher, K., $\mathrm{Xu}$, Y., Wang, M-W., Xu, H. E. \& Jiang, Y. Crystal structure of the human 5-HT $1 \mathrm{~B}$ serotonin receptor bound to an inverse agonist. Cell Discov. 4, 1-13 (2018). 
We appreciate Drs. S. Gulati and M. Singh for helpful comments on the manuscript. We thank Kayo Sato, Shigeko Nakano and Ayumi Inoue (Tohoku University) for their assistance with plasmid preparation, maintenance of cell culture and cell-based GPCR assays. This work was supported by JSPS KAKENHI, Japan, grant numbers 18K14662 to K.K., 18H03986, 19H04959 to H.K., $15 \mathrm{~K} 08268,19 \mathrm{H} 03428$ to R.S., $19 \mathrm{H} 05777$ to S.I.; the Naito Science \& Engineering

567 Foundation to K.K.; the Takahashi Industrial and Economic Research Foundation to K.K.; the Takeda Science Foundation to T.K. and R.S.; the Naito Foundation to T.K.; the Koyanagi

569 Foundation to T.K.; the Basis for Supporting Innovative Drug Discovery and Life Science 570 Research (BINDS) from the Japan Agency for Medical Research and Development (AMED) 571 under grant number JP20am0101079 to S.I. and JP20am0101095 to A.I.; AMED under grant number JP20gm0910007, JP20am0401020, and JP20ak0101103 to T.K. and the LEAP JP20gm0010004 to A.I.; and Japan Science and Technology Agency (JST) PRESTO (JPMJPR19G4) to K.K.

\section{Author Contributions}

K.K., K.S., R.S., A.I., and H.K. contributed to the study design. R.S. and H.T. expressed samples in Sf9 and purified them. K.K. and K.S. reconstituted samples for spectroscopic

580 measurements. K.K. and K.S. conducted ATR-FTIR spectroscopic measurements. R.K. and A.I.

581 performed NanoBiT G-protein dissociation assay. K.K. prepared the initial manuscript and K.K., 
K.S., R.S., R.K., S.I., A.I., T.K. and H.K. wrote the paper with input from all the authors. All

583 authors discussed and commented on the manuscript.

\section{Additional information}

Supplementary Information accompanies this paper at https://www.nature.com/ncomms/

Competing financial interests: The authors declare no competing financial interests.

permission information

is available

online

at http://npg.nature.com/reprintsandpermissions/

Figures

Figure 1. Ligand binding-induced difference ATR-FTIR spectra measurement on ligands with different efficacies for $\mathbf{M}_{2} \mathbf{R}$. (a) Chemical structures of the ligands used in the ATR-FTIR spectroscopy measurements. Common features among each ligand are marked by dashed circles. (b) Ligand binding-induced difference ATR-FTIR spectra of $\mathrm{M}_{2} \mathrm{R}$ bound with agonist-, antagonist-, and inverse agonist-bound spectra measured in $\mathrm{H}_{2} \mathrm{O}$, respectively. Positive

600 and negative bands originate from ligand-bound and ligand-unbound states, respectively. One 601 division of the y-axis corresponds to 0.002 absorbance unit.

602

Figure 2. Ligand-dependent spectral changes in the $\alpha$-helical region of $M_{2} R$ and relative populations of active and inactive states of $\mathbf{M}_{2} \mathbf{R}$. (a) Ligand binding-induced difference ATR-FTIR spectra in the $1800-1200 \mathrm{~cm}^{-1}$ region, especially focusing on amide-I band 606 region, which are taken from Fig. 1B. Red and purple lines correspond to ACh- and Atro-bound 
spectra, respectively. To quantitatively examine the change in the amide-I band specific to ligand efficacy, the ratio between the band strength of (2)1656 (+)/(1)1666 (-) $\mathrm{cm}^{-1}$ of ACh-bound spectra at high frequency and (2)1656 (+)/(3)1640 (-) $\mathrm{cm}^{-1}$ of ACh-bound spectra at low frequency is calculated and reported as efficacy rate. (b) Ligand-dependent spectral changes of amide-I band originating from $\mathrm{C}=\mathrm{O}$ stretch of $\alpha$-helix in $1700-1620 \mathrm{~cm}^{-1}$ region. Red, orange, and purple lines correspond to agonist-, partial agonist-, and antagonist-bound spectra, respectively. One division of the y-axis corresponds to 0.002 absorbance unit. (c) Relative populations of active and inactive states upon ligand binding in $\mathrm{M}_{2} \mathrm{R}$ derived by the equation of efficacy rate from (A). The error values were calculated from three replicate experiments. Cyan dotted line indicates the value $=1$.

\section{Figure 3. Correlation between ligand efficacy and amide-I percent population. (a)}

Efficacies of the different $\mathrm{M}_{2} \mathrm{R}$ ligands toward $\mathrm{G}_{\mathrm{i}}$ activation in the NanoBiT G-protein dissociation assay. $E_{\max }$ values were calculated from the concentration-response sigmoidal curves in Extended Data Figure 6 and were normalized to that of ACh performed in parallel. Bars and error bars represent mean and SEM, respectively, of 5 or 10 (shown in parenthesis) independent experiments with each performed in duplicate. (b) Correlation between ligand efficacy and the relative intensities of the amide-I bands. The relative intensities of the amide-I bands are calculated by the equation of efficacy rate, which is derived from Figure 2c. Ligand efficacy is determined by the NanoBiT G-protein dissociation assay from (a). Agonists (ACh, Meta, Are, and Carb) are shown as red circles, partial agonists (Pilo, $\mathrm{McN}$, and Xano) as orange circles, and antagonists (Atro, Scop, and Ipra) as purple circles highlighted by light purple.

Figure 4. Ligand-dependent dissociation kinetics on $\mathbf{M}_{2} \mathbf{R}$. (a) Time trace of the integrated absorbance signal in the amide-I band (red circle, ACh; purple circle, Atro) taken from 
Ref 32. Ligand dissociation phase is highlighted by light blue. (b) Time trace of the integrated absorbance signal at dissociation phase in the amide-I band for each ligand. Time-dependent difference ATR-FTIR spectra upon ligand dissociation in the amide-I region (1680-1630 $\left.\mathrm{cm}^{-1}\right)$ are shown in Extended Data Fig. 8. Black red, orange, purple, and cyan correspond to ACh, agonist, partial agonist, antagonist, and inverse agonist, respectively. Black dotted line represents the fitting curve obtained by single exponential function.

\section{Figure 5. Proposed conformational changes in $M_{2} R$ upon binding of ligands with} different efficacies. (Upper) Schematic of $\mathrm{M}_{2} \mathrm{R}$ TM6 and TM5 conformational states upon binding of orthosteric ligands with different efficacies. TM6 features an open conformation in the extracellular side and a closed conformation in the cytoplasmic side upon binding with inverse agonist and antagonist. In contrast, TM6 features a closed conformation in the extracellular side and an open conformation in the cytoplasmic side upon binding with both agonist and partial agonist, which causes the opposite movement with both inverse agonist and antagonist. Yellow dotted line indicates the orthosteric ligand binding pocket. (Lower) Schematic of $\mathrm{M}_{2} \mathrm{R}$ ligand binding pocket surrounded by TM3, 5, 6, and 7. Two key amino acids (Asn404 ${ }^{6.52}$ and Asp103 $3^{3.32}$ ) and tyrosine lid are depicted by star and oval markers, respectively. Binding of either inverse agonist or antagonist opens the extracellular region of TM6, resulting in loosening of the tyrosine lid, whereas both agonist- and partial agonist-bound forms compacts the ligand-binding pocket, which induces the formation of tyrosine lid that excludes solvent entry.

Figure 6. Comparison between the scopolamine derivatives. (a) Chemical structures of the scopolamine derivative ligands (Scopolamine (Scop), N-butylscopolamine (NBS), Oxitropium (Oxitro), and N-methylscopolamine (NMS)) used in the current FTIR spectroscopic studies, and each ligand bound spectra in the $1800-1450 \mathrm{~cm}^{-1}$ region. The group of quaternary 
ammonium derivative positions are highlighted. Ligand binding-induced difference ATR-FTIR

658 spectra are measured in $\mathrm{H}_{2} \mathrm{O}$ at $293 \mathrm{~K}$. Positive and negative bands correspond to ligand-bound 659 and ligand-unbound states, respectively. One division of the y-axis corresponds to 0.0025 660 absorbance unit. (b) Comparison between Atro-bound structure in $\mathrm{M}_{1} \mathrm{R}$ (green, PDB: 6WJC) ${ }^{42}$ 661 and NMS-bound structure in $\mathrm{M}_{2} \mathrm{R}$ (cyan, PDB: $\left.5 \mathrm{YC} 8\right)^{15}$ at the view from extracellular side. The 662 amino acid residues and ligands are depicted by sticks, and TM helices are depicted by ribbons. 663 Hydrogen bond between Asp103.32 and amine group of both ligands are shown by red dotted 664 lines with hydrogen bond length as labels.

Extended Data Figures

Extended Data Fig. 1. Comparison of IR absorption of each ligand. (a) Red and grey lines represent agonist binding-induced difference ATR-FTIR spectra with empty liposome but without protein and without both protein and empty liposome in the $1800-1150 \mathrm{~cm}^{-1}$, respectively. One division of the $y$-axis corresponds to 0.0003 absorbance unit. (b) Orange and grey lines represent partial agonist binding-induced difference ATR-FTIR spectra with empty liposome but without 674 protein and without both protein and empty liposome in the $1800-1150 \mathrm{~cm}^{-1}$, respectively. One 675 division of the y-axis corresponds to 0.001 absorbance unit. (c) Purple and grey lines represent antagonist binding-induced difference ATR-FTIR spectra with empty liposome but without 677 protein and without both protein and empty liposome in the $1800-1150 \mathrm{~cm}^{-1}$, respectively. One 678 division of the y-axis corresponds to 0.0005 absorbance unit. (d) Cyan and grey lines represent 679 agonist binding-induced difference ATR-FTIR spectra with empty liposome but without protein 680 and without both protein and empty liposome in the $1800-1150 \mathrm{~cm}^{-1}$, respectively. One division 681 of the y-axis corresponds to 0.0015 absorbance unit. 
684 Extended Data Fig. 2. The agonist binding-induced difference ATR-FTIR spectra in the $6854000-1000 \mathrm{~cm}^{-1}$ region. The absorption of unbound ligands (shaded grey), the absorption of 686 phosphate buffer (shaded green), the absorption of water (shaded cyan) and the absorption of $\mathrm{CO}_{2}$ 687 (shaded yellow) are subtracted for spectral correction.

689 Extended Data Fig. 3. The partial agonist binding-induced difference ATR-FTIR spectra in the $6904000-1000 \mathrm{~cm}^{-1}$ region. The absorption of unbound ligands (shaded grey), the absorption of 691 phosphate buffer (shaded green), the absorption of water (shaded cyan) and the absorption of $\mathrm{CO}_{2}$ 692 (shaded yellow) are subtracted for spectral correction.

Extended Data Fig. 4. The antagonist binding-induced difference ATR-FTIR spectra in the 4000-1000 $\mathrm{cm}^{-1}$ region. The absorption of unbound ligands (shaded grey), the absorption of phosphate buffer (shaded green), the absorption of water (shaded cyan) and the absorption of $\mathrm{CO}_{2}$

697 (shaded yellow) are subtracted for spectral correction.

Extended Data Fig. 5. The inverse agonist binding-induced difference ATR-FTIR spectra in 700 the $4000-1000 \mathrm{~cm}^{-1}$ region. The absorption of unbound ligands (shaded grey), the absorption of 701 phosphate buffer (shaded green), the absorption of water (shaded cyan) and the absorption of $\mathrm{CO}_{2}$ (shaded yellow) are subtracted for spectral correction.

Extended Data Fig. 6. Concentration-response curves of $\mathrm{G}_{i}$ activation in NanoBiT G-protein dissociation assay of $\mathrm{M}_{2} \mathrm{R}$. Symbols and error bars represent mean and SEM, respectively, of 5 or 10 (shown in parenthesis) independent experiments with each performed in duplicate. 
708 Extended Data Fig. 7. (a) Potency of the different $\mathrm{M}_{2} \mathrm{R}$ ligands toward $\mathrm{G}_{\mathrm{i}}$ activation in the 709 NanoBiT G-protein dissociation assay. pEC50 values were calculated from the 710 concentration-response sigmoidal curves in Extended Data Figure 6. Bars and error bars represent 711 mean and SEM, respectively, of 5 or 10 (shown in parenthesis) independent experiments with 712 each performed in duplicate. (b) Plot of the amide-I percent population for agonists, partial 713 agonists, and antagonists against their potency toward $\mathrm{G}_{\mathrm{i}}$ activation in the NanoBiT G-protein 714 dissociation assay. The amide-I percent population values were calculated by the equation of 715 efficacy rate, which was derived from Figure 2c, and pEC50 values were derived from (a). 716 Agonists (ACh, Meta, Are, and Carb) were shown as red circles, partial agonists (Pilo, McN, and 717 Xano) as orange circles, and antagonists (Atro, Scop, and Ipra) as purple circles.

Extended Data Fig. 8. Time-dependent difference ATR-FTIR spectra upon agonist (1st panel), partial agonist (2nd panel), antagonist (3rd panel) and inverse agonist (4th panel) dissociating in 721 the amide-I (at $1680-1630 \mathrm{~cm}^{-1}$ ) region.

Extended Data Fig. 9. Schematic drawing of binding fashion between antagonist and inverse agonist. Pale purple squares indicate the different moiety in tropane alkaloid among each ligand;

(Oxitro), and N-methylscopolamine (NMS). Pale cyan squares indicate the common chemical moiety among each ligand. Only NMS can fit the length between TM3 and TM6, which adopts an energetically favourable binding fashion to $\mathrm{M}_{2} \mathrm{R}$ resulting in reducing the receptor activity at negative value. 


\section{Figures}
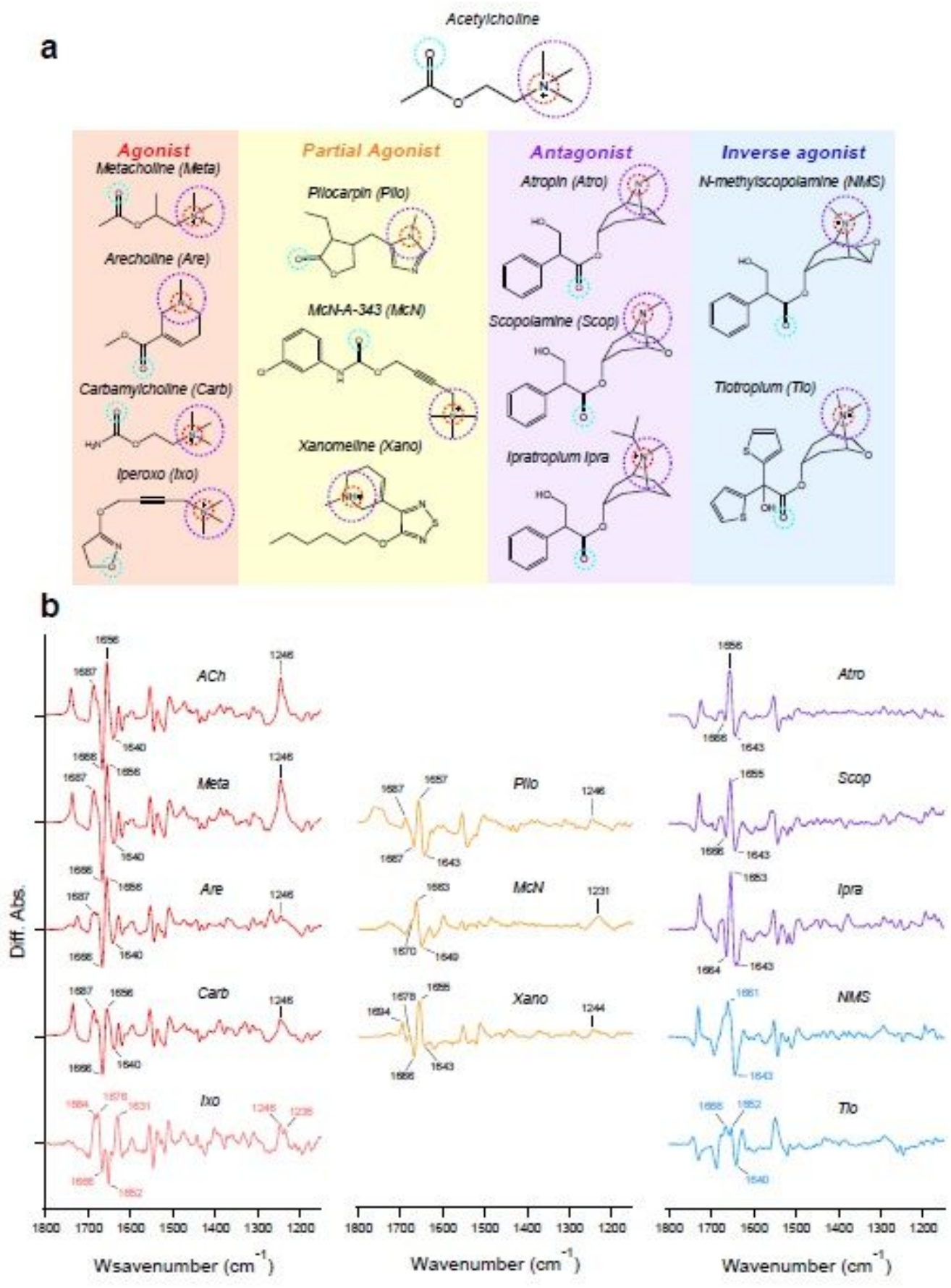

\section{Figure 1}

Ligand binding-induced difference ATR-FTIR spectra measurement on ligands with different efficacies for M2R. (a) Chemical structures of the ligands used in the ATR-FTIR spectroscopy measurements. Common features among each ligand are marked by dashed circles. (b) Ligand binding-induced difference ATRFTIR spectra of M2R bound with various ligands at $293 \mathrm{~K}$. Red, orange, purple, and cyan lines correspond to agonist-, partial agonist-, antagonist-, and inverse agonist-bound spectra measured in $\mathrm{H} 2 \mathrm{O}$, 
respectively. Positive and negative bands originate from ligand-bound and ligand-unbound states, respectively. One division of the $y$-axis corresponds to 0.002 absorbance unit.

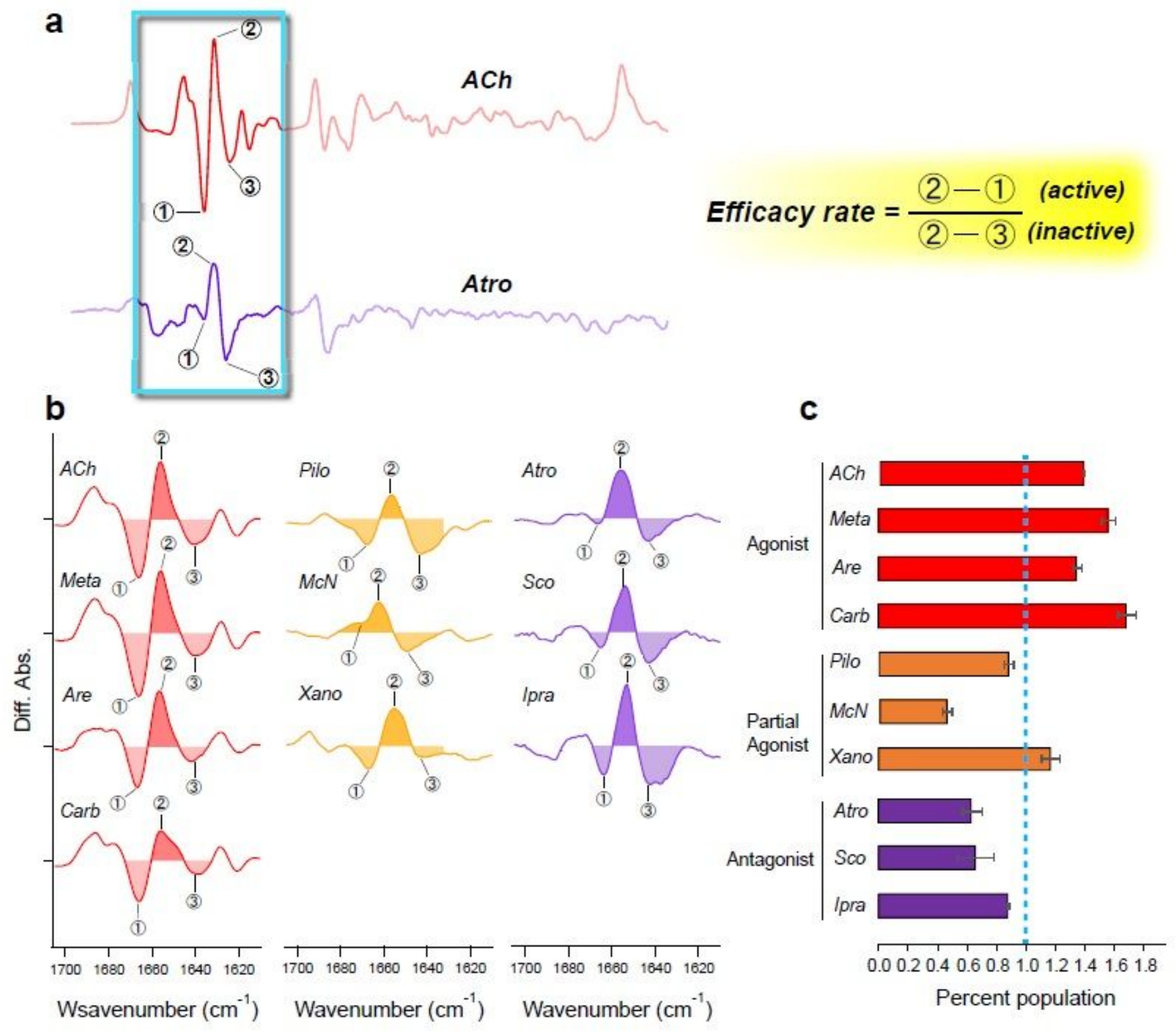

\section{Figure 2}

Ligand-dependent spectral changes in the a-helical region of M2R and relative populations of active and inactive states of M2R. (a) Ligand binding-induced difference ATR-FTIR spectra in the 1800-1200 cm-1 region, especially focusing on amide-l band region, which are taken from Fig. 1B. Red and purple lines correspond to ACh- and Atro-bound spectra, respectively. To quantitatively examine the change in the amide-I band specific to ligand efficacy, the ratio between the band strength of (2)1656 (+)/(1)1666 (-) cm-1 of ACh-bound spectra at high frequency and (2)1656 (+)/(3)1640 (-) cm-1 of ACh-bound spectra at low frequency is calculated and reported as efficacy rate. (b) Ligand-dependent spectral changes of amide-I band originating from $\mathrm{C}=0$ stretch of a-helix in $1700-1620 \mathrm{~cm}-1$ region. Red, orange, and purple 
lines correspond to agonist-, partial agonist-, and antagonist-bound spectra, respectively. One division of the $y$-axis corresponds to 0.002 absorbance unit. (c) Relative populations of active and inactive states upon ligand binding in M2R derived by the equation of efficacy rate from $(A)$. The error values were calculated from three replicate experiments. Cyan dotted line indicates the value $=1$.
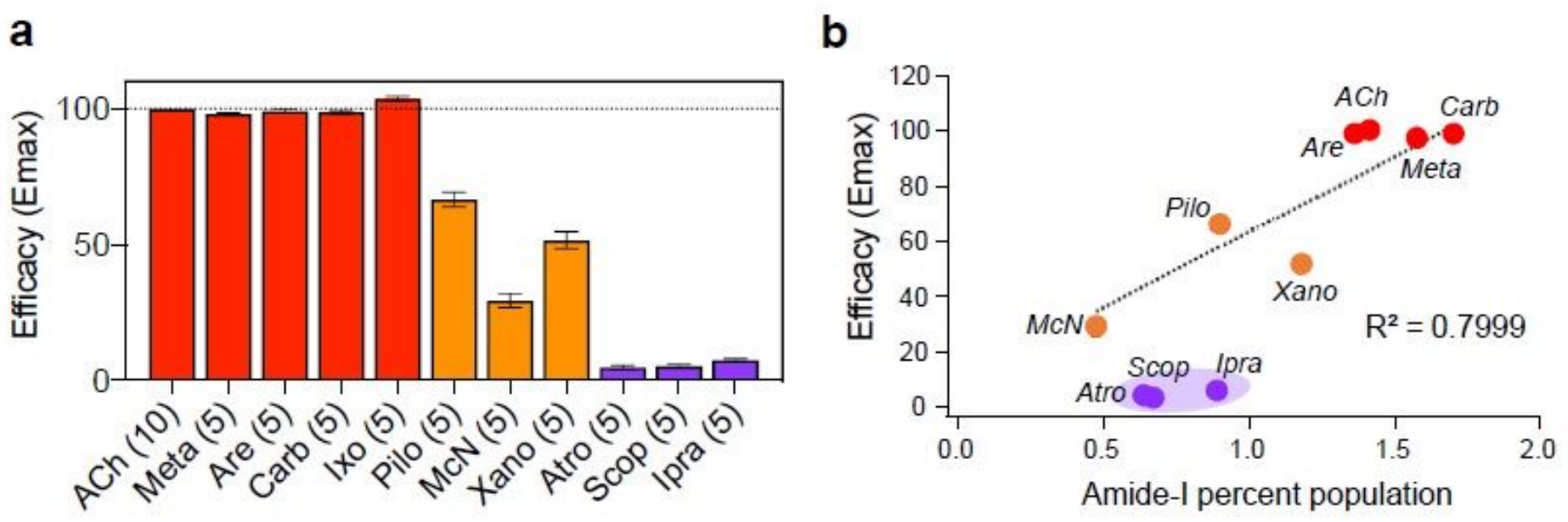

\section{Figure 3}

Correlation between ligand efficacy and amide-I percent population. (a) Efficacies of the different M2R ligands toward $\mathrm{Gi}$ activation in the NanoBiT G-protein dissociation assay. Emax values were calculated from the concentration-response sigmoidal curves in Extended Data Figure 6 and were normalized to that of ACh performed in parallel. Bars and error bars represent mean and SEM, respectively, of 5 or 10 (shown in parenthesis) independent experiments with each performed in duplicate. (b) Correlation between ligand efficacy and the relative intensities of the amide-l bands. The relative intensities of the amide-l bands are calculated by the equation of efficacy rate, which is derived from Figure 2c. Ligand efficacy is determined by the NanoBiT G-protein dissociation assay from (a). Agonists (ACh, Meta, Are, and Carb) are shown as red circles, partial agonists (Pilo, McN, and Xano) as orange circles, and antagonists (Atro, Scop, and Ipra) as purple circles highlighted by light purple. 
a

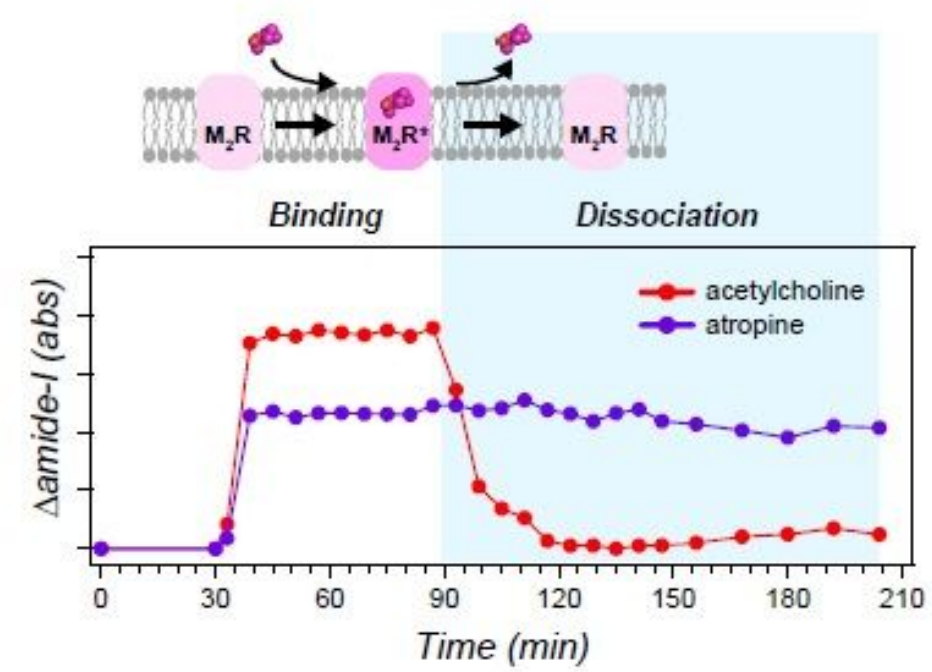

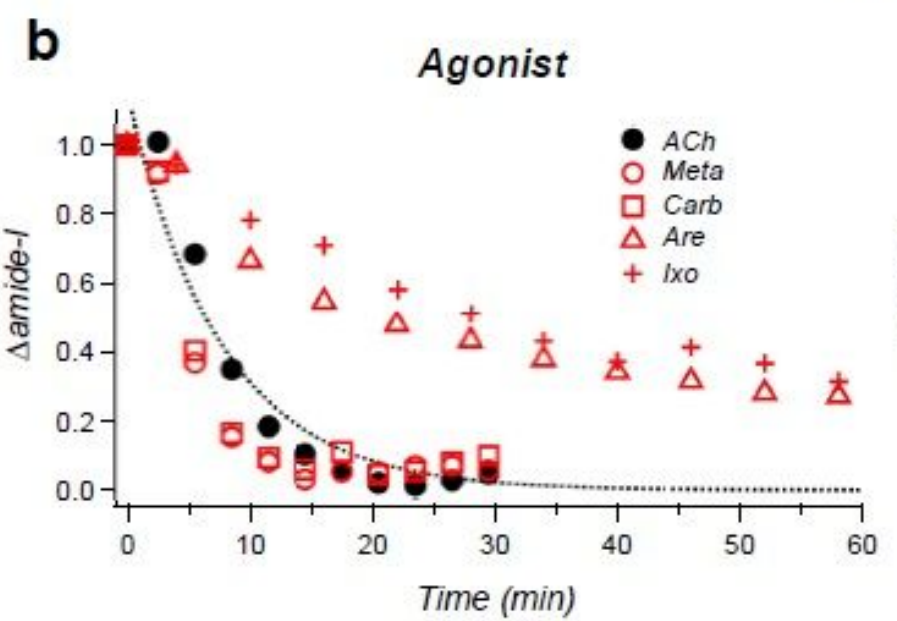

Antagonist

Partial agonist

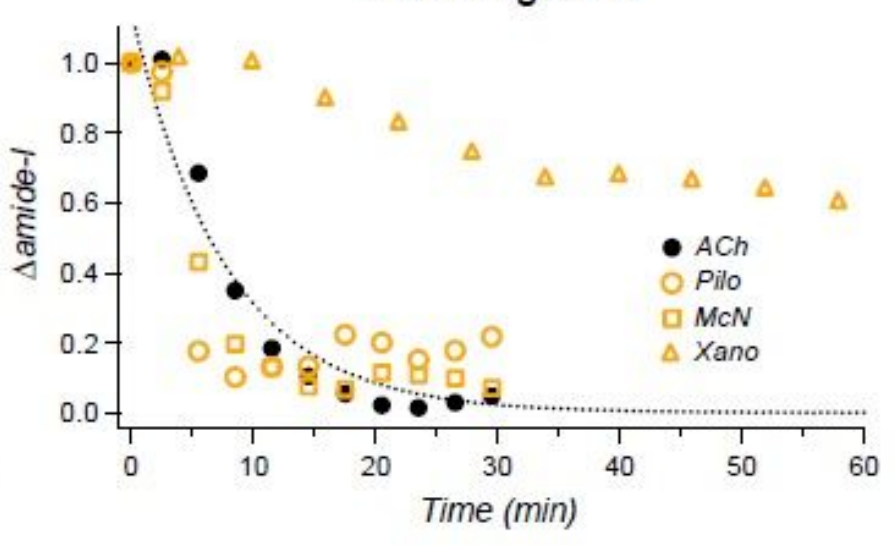

Inverse agonist
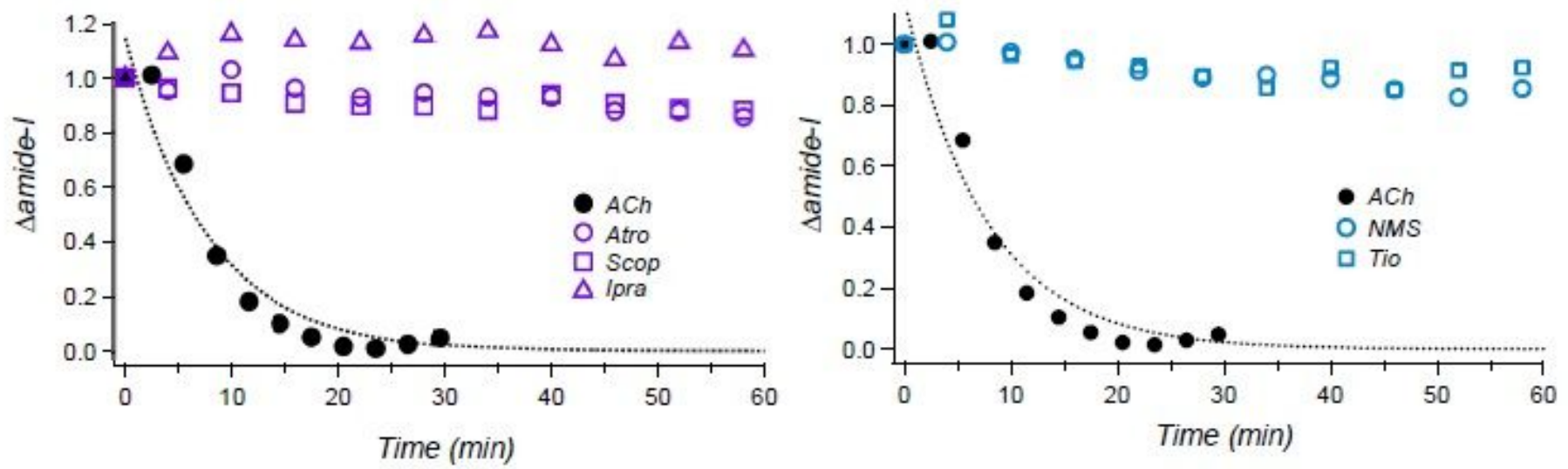

\section{Figure 4}

Ligand-dependent dissociation kinetics on M2R. (a) Time trace of the integrated absorbance signal in the amide-I band (red circle, ACh; purple circle, Atro) taken from Ref 32. Ligand dissociation phase is highlighted by light blue. (b) Time trace of the integrated absorbance signal at dissociation phase in the amide-I band for each ligand. Time-dependent difference ATR-FTIR spectra upon ligand dissociation in the amide-I region (1680-1630 cm-1) are shown in Extended Data Fig. 8. Black red, orange, purple, and 
cyan correspond to ACh, agonist, partial agonist, antagonist, and inverse agonist, respectively. Black dotted line represents the fitting curve obtained by single exponential function.

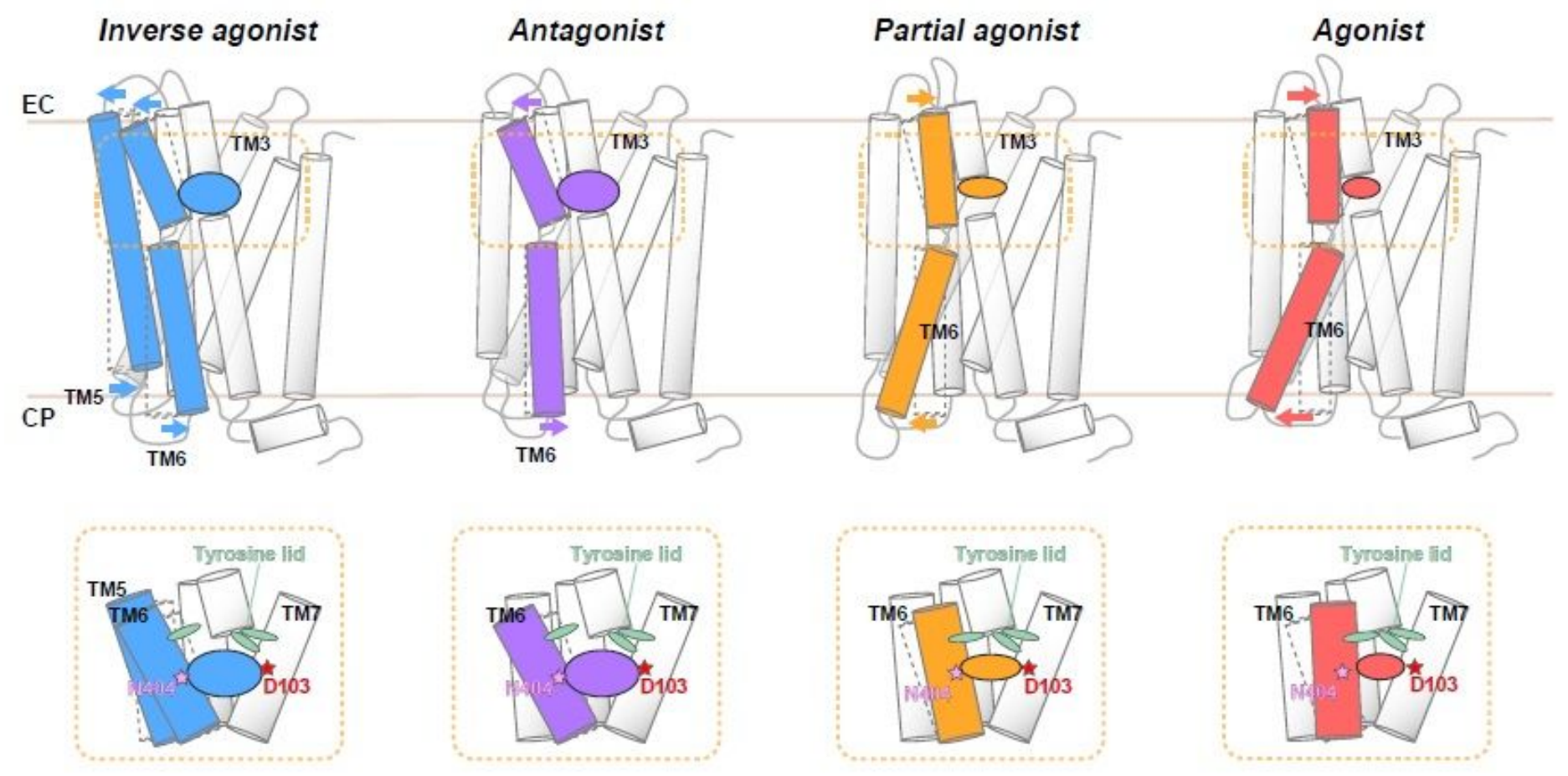

Figure 5

Proposed conformational changes in M2R upon binding of ligands with different efficacies. (Upper) Schematic of M2R TM6 and TM5 conformational states upon binding of orthosteric ligands with different efficacies. TM6 features an open conformation in the extracellular side and a closed conformation in the cytoplasmic side upon binding with inverse agonist and antagonist. In contrast, TM6 features a closed conformation in the extracellular side and an open conformation in the cytoplasmic side upon binding with both agonist and partial agonist, which causes the opposite movement with both inverse agonist and antagonist. Yellow dotted line indicates the orthosteric ligand binding pocket. (Lower) Schematic of M2R ligand binding pocket surrounded by TM3, 5, 6, and 7. Two key amino acids (Asn4046.52 and Asp1033.32) and tyrosine lid are depicted by star and oval markers, respectively. Binding of either inverse agonist or antagonist opens the extracellular region of TM6, resulting in loosening of the tyrosine lid, whereas both agonist- and partial agonist-bound forms compacts the ligandbinding pocket, which induces the formation of tyrosine lid that excludes solvent entry. 

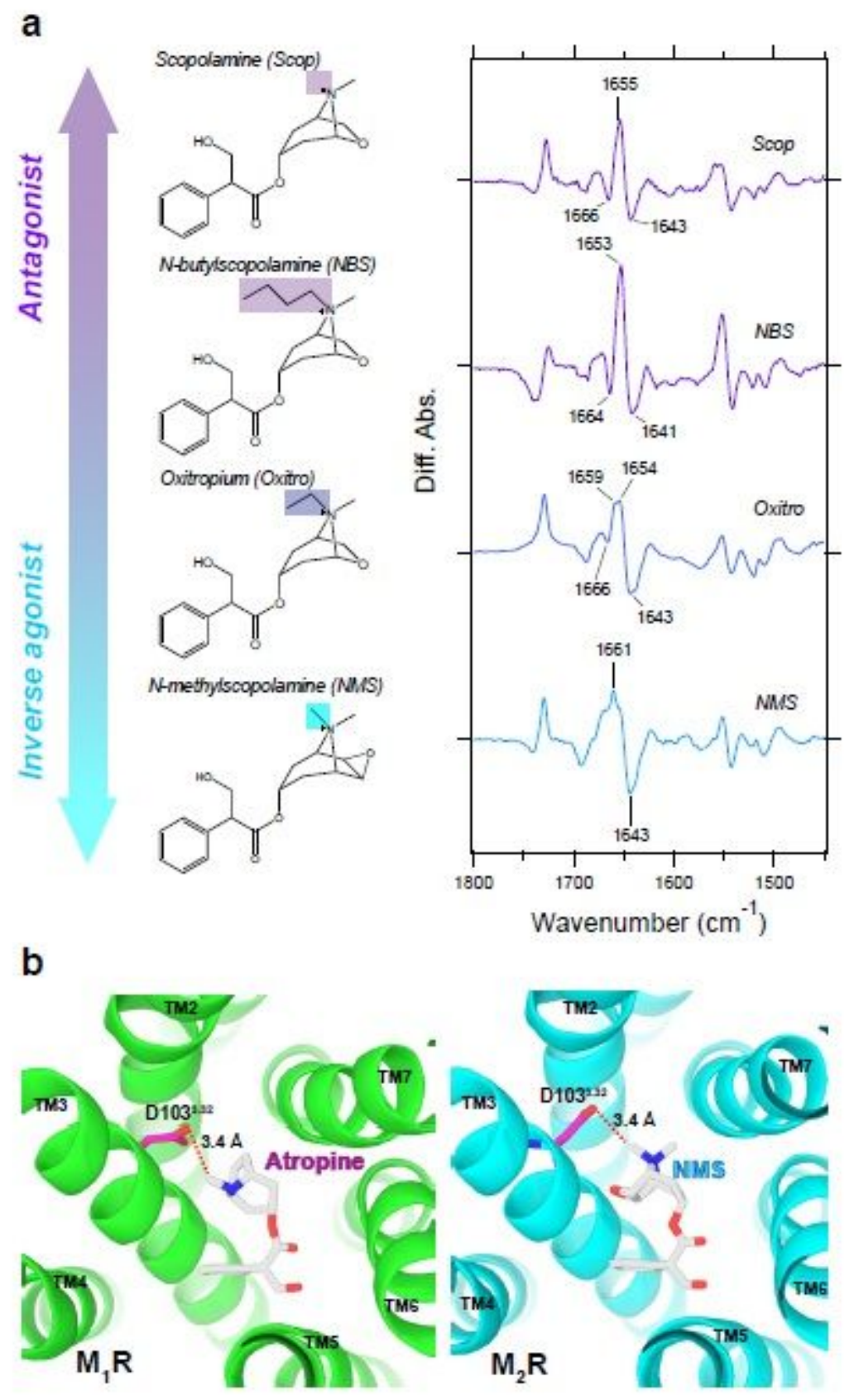

\section{Figure 6}

Comparison between the scopolamine derivatives. (a) Chemical structures of the scopolamine derivative ligands (Scopolamine (Scop), N-butylscopolamine (NBS), Oxitropium (Oxitro), and N-methylscopolamine (NMS)) used in the current FTIR spectroscopic studies, and each ligand bound spectra in the 1800-1450 $\mathrm{cm}-1$ region. The group of quaternary ammonium derivative positions are highlighted. Ligand bindinginduced difference ATR-FTIR spectra are measured in H2O at $293 \mathrm{~K}$. Positive and negative bands correspond to ligand-bound and ligand-unbound states, respectively. One division of the y-axis corresponds to 0.0025 absorbance unit. (b) Comparison between Atro-bound structure in M1R (green, PDB: 6WJC)42 and NMS-bound structure in M2R (cyan, PDB: 5YC8)15 at the view from extracellular side. 
The amino acid residues and ligands are depicted by sticks, and TM helices are depicted by ribbons. Hydrogen bond between Asp1033.32 and amine group of both ligands are shown by red dotted lines with hydrogen bond length as labels.

\section{Supplementary Files}

This is a list of supplementary files associated with this preprint. Click to download.

- M2ligandscreeningSupportingFiguresv2.pdf 